\section{Imaging of Facial Fillers: Additional Insights}

We appreciate the interest that readers have expressed in our article "Imaging Features of Midface Injectable Fillers and Associated Complications," 1 and we are pleased to be regarded as pioneers in the field. However, we would like to clarify a few points and share additional insights on the subject.

Our review article certainly shows the utility of CT and MR imaging for depicting many of the early and late complications associated with facial fillers besides foreign-body granulomas. ${ }^{1}$ In particular, we have, on occasion, received requests to delineate the extent of filler material, especially when migration has occurred. Indeed, some of these cases are shown in our article.

Although facial fillers may appear different from one patient to another and can change with time (Fig 1), certain fundamental imaging characteristics of facial fillers can be surmised. This is the case in many other areas of radiology in which pattern-recognition applies. Although imaging is not intended simply to differentiate the types of facial filler materials, some of these have rather distinctive appearances.

Although uncommon, scar formation is a known complication of facial fillers. This phenomenon has been previously described with silicone and Artecoll (Suneva Medical, San Diego, California), for example: "Siliconomas and scarring can occur after a variable delay after the silicone injections, ranging from 3 weeks to a decade.... If Artecoll (collagen and polymethylmethacrylate) is injected too superficially, it can lead to persistent itchiness, redness and even hypertrophic scarring that may need to be reduced by local corticosteroid injections."

With regard to the hypermetabolism associated with injection of a calcium hydroxylapatite filler, this can be a source of false-positive findings on PET. ${ }^{3,4}$ We have also noted hypermetabolism associated with fillers other than calcium hydroxylapatite (Fig 2), suggestive of an inflammatory response that can be subclinical.

The study of facial fillers is an evolving multidisciplinary field with many questions remaining to be answered.

\section{References}

1. Ginat DT, Schatz CJ. Imaging features of midface injectable fillers and associated complications. AJNR Am J Neuroradiol 2012 Jul 26 [Epub ahead of print]

2. Lafaille P, Benedetto A. Fillers: contraindications, side effects and precautions. J Cutan Aesthet Surg 2010;3:16-19

3. Damrose EJ. Radiographic properties of injected calcium hydroxylapatite: potential false positive findings on positron emission tomography. J Laryngol Otol 2008;122:1394-96

4. Feeney JN, Fox JJ, Akhurst T. Radiological impact of the use of calcium hydroxylapatite dermal fillers. Clin Radiol 2009;64:897-902

http://dx.doi.org/10.3174/ajnr.A3394 


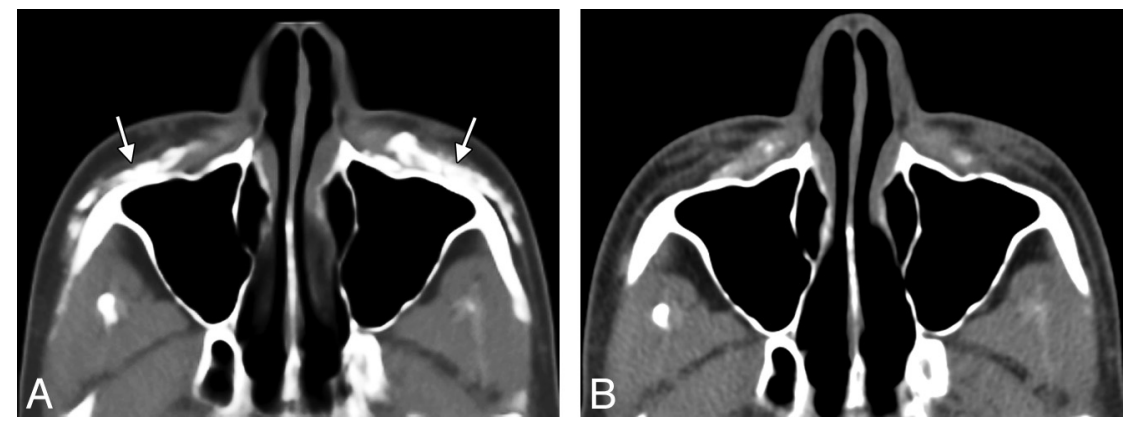

Fig 1. Axial CT image $(A)$ shows hyperattenuated deposits of calcium hydroxylapatite within the bilateral cheeks (arrows). Axial CT image obtained 22 months (B) later shows significant interval decrease in the hyperattenuated deposits.

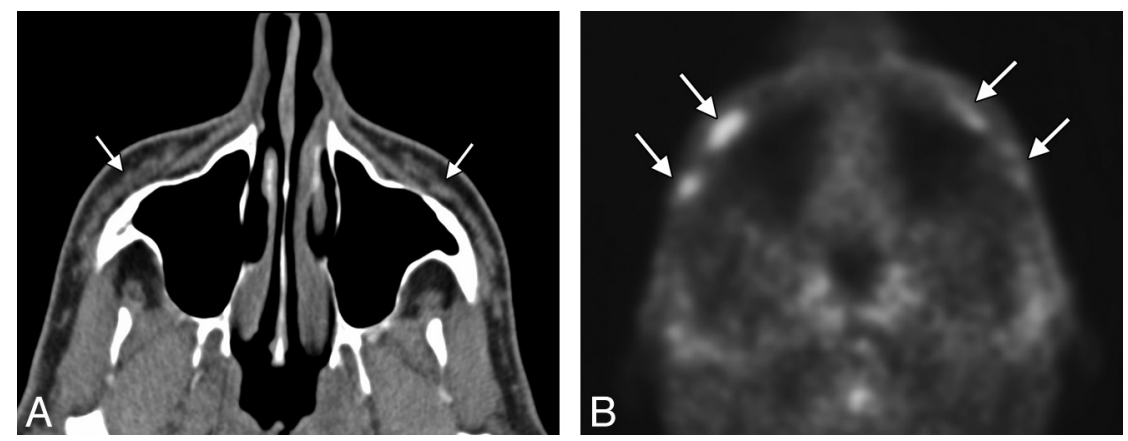

Fig 2. Axial CT image $(A)$ shows nearly fluid-attenuation filler material within the bilateral cheeks (arrows). PET image (B) shows hypermetabolic foci within the cheek subcutaneous tissues corresponding to reported collagen-based fillers (arrows). However, the patient did not have symptoms related to this finding, and no biopsy was performed.

D.T. Ginat

Department of Radiology

Massachusetts General Hospital, Harvard Medical School Boston, Massachusetts

C.J. Schatz

Beverly Tower Wilshire Advanced Imaging Beverly Hills, California University of Southern California Keck School of Medicine Los Angeles, California 